\title{
Cervical spine instability in the course of rheumatoid arthritis - imaging methods
}

\author{
Małgorzata Mańczak ${ }^{1}$, Robert Gasik ${ }^{2}$ \\ ${ }^{1}$ Department of Gerontology, Public Health and Didactics, National Institute of Geriatrics, Rheumatology and Rehabilitation, Warsaw, \\ Poland \\ ${ }^{2}$ Clinic and Polyclinic of Neuroorthopedy and Neurology, National Institute of Geriatrics, Rheumatology and Rehabilitation, Warsaw, \\ Poland
}

\begin{abstract}
Cervical spine is affected in more than a half of patients with rheumatoid arthritis (RA). Depending on the degree of damage to the individual joints and ligaments RA-related cervical spine instability takes the form of atlanto-axial subluxation, subaxial subluxation or cranial settling. In the advanced cases spinal stenosis can occur as well as spinal cord injuries with typical neurological symptoms. The identification of patients with cervical spine instability before the occurrence of neurological complications still constitutes a diagnostic challenge.

The article presents the methods of cervical spine imaging with the use of plain radiographs, magnetic resonance imaging (MRI) and computed tomography (CT). We discuss the advantages and disadvantages associated with each method and the possibility of its application in the diagnosis of cervical spine instability in RA. The knowledge of the above mentioned issues is indispensable to select an appropriate time for surgical intervention.
\end{abstract}

Key words: rheumatoid arthritis, imaging, cervical spine.

\section{Introduction}

The inflammatory processes in rheumatoid arthritis (RA) affect mostly joints of hands and feet. Cervical spine is the third most common location of lesions in the course of RA. Pathological lesions in cervical spine structure are observed in 44-86\% of patients with RA [1-4].

In RA the upper cervical spine is usually affected, which is manifested by the instability between $\mathrm{C} 1$ and C2 vertebrae (atlanto-axial subluxation - AAS) occurring in $65 \%$ of patients with RA. Anterior subluxation occurs most often (ca. $75 \%$ of all AAS); posterior and lateral are not that often. Moreover in ca. $20 \%$ of patients subluxation of the spinal motion segment can occur at the C3 to C7 vertebrae (subaxial subluxation, SAS) [4-7]. Cranial settling $(\mathrm{CrS})$ is another pathology of cervical spine that occurs in patients with RA and is described in ca. 15\% of patients $[3,8]$. Definitions of the respective types of cervical spine instability are presented in Table I.
Lesions in cervical spine can manifest as the pain in the neck, nape of the neck and head. In more advanced cases they may lead to neurological defects, i.e. sensory disturbances, muscle weakness and even to death. In some cases serious consequences related to the impact of RA on the cervical spine require surgical treatment. Correct qualification for surgery as well as early diagnosis are possible only when based on precise diagnostics including imaging.

\section{Diagnostic methods}

Imaging methods used in the diagnostics of cervical spine lesions in patients with RA are primarily plain radiographs, computed tomography and magnetic resonance imaging. Each of these methods is used to assess the cervical spine from a slightly different perspective, having its advantages and disadvantages. 
Table I. Types of cervical spine instability

\begin{tabular}{|c|c|}
\hline Type of instability & \\
\hline $\begin{array}{l}\text { AAS } \\
\text { atlanto axial subluxation }\end{array}$ & $\begin{array}{l}\text { instability in atlanto-axial joints due to the weakening of the structure or rupture of ligaments as } \\
\text { well as subchondral bone ulceration } \\
\text { - anterior - occurring in the anterior median atlanto-axial joint, located between anterior arch of } \\
\mathrm{C} 1 \text { and the dens of the axis } \\
\text { - posterior - occurring in the posterior median atlanto-axial joint, located between posterior arch } \\
\text { of } \mathrm{C} 1 \text { and the dens of the axis } \\
\text { - lateral - asymmetrical or unilateral changes of the lateral atlanto-axial joint leading to impair- } \\
\text { ment in rotation }\end{array}$ \\
\hline $\begin{array}{l}\text { SAS } \\
\text { subaxial subluxation }\end{array}$ & $\begin{array}{l}\text { subluxation occurring in joints on } \mathrm{C} 3-\mathrm{C} 7 \text { level due to the destruction of articular surface and } \\
\text { ligaments between spinous processes }\end{array}$ \\
\hline $\begin{array}{l}\text { CrS } \\
\text { cranial settling }\end{array}$ & superior migration of the odontoid into foramen magnum \\
\hline
\end{tabular}

\section{Plain Radiographs}

Radiography is the most common technique, mainly due to its availability and relatively low cost. Typically, radiographs are made in antero-posterior projection, lateral projection (neutral position as well as flexion and extension - the so-called functional radiograph) as well as through the open mouth aimed at the odontoid process. While analysing the radiographs spatial relations between the bones of the vertebral column and the head as well as structural lesions can be assessed. As the anomalies in the atlanto-axial joint are distinctly seen when changing the head position, functional radiographs are the most important for the instability diagnosis. When comparing the radiograph in neutral position with flexion and extension, possible move of the odontoid process to the spinal canal, displacement of vertebrae and spinal stenosis can be observed. Functional radiographs are initial method for the instability diagnosis and often determine further neurosurgical management [9].

\section{Atlanto-axial subluxation}

Anterior atlantodental interval (AADI) and posterior atlantodental interval (PADI) are the most important values used to evaluate the condition of the atlanto-axial joint [10]. The distance is measured based on lateral radiograph in three positions: neutral, flexion and extension (Fig. 1).

Anterior atlantodental interval is the distance between C1 anterior arch and C2 of the dens. The normal value of AADI in adults should be less than $3 \mathrm{~mm}$. The larger AADI, the greater risk of spinal cord compression. Some authors consider that AADI $>5 \mathrm{~mm}$ is a sign of clinically significant AAS instability [11], and AADI > $8 \mathrm{~mm}$ is an indication for surgical treatment [12]. It should be
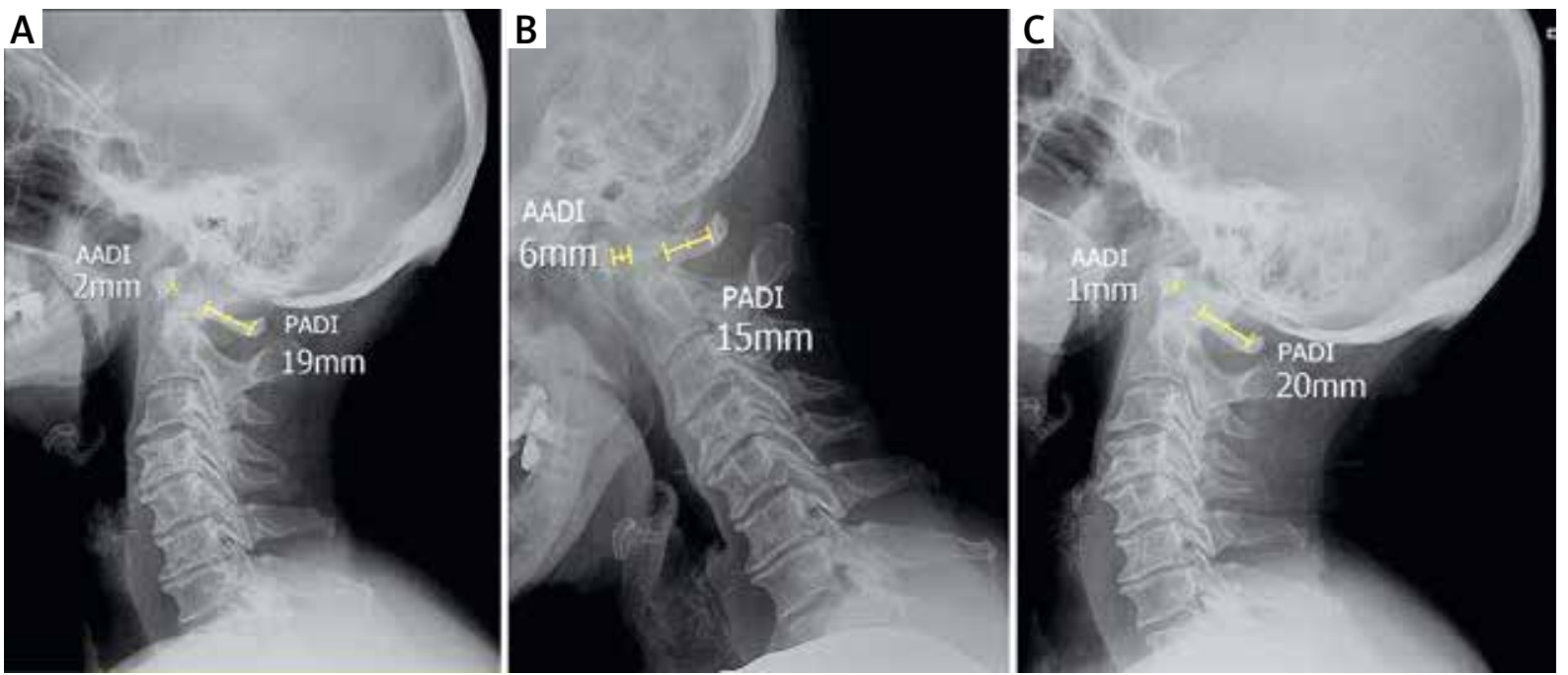

Fig. 1. Lateral neutral (A), flexion (B) and extension (C) radiographs. 
noted that these values apply to adults - the normal value of AADI in children is up to $5 \mathrm{~mm}$ [13].

Posterior atlantodental interval is the distance between the dens and $\mathrm{C} 1$ posterior arch. The distance is the width of the spinal canal on the C1-C2 level. As the spinal cord at this level is ca. $10 \mathrm{~mm}$ in diameter, $1 \mathrm{~mm}$ is needed for the dura and $1 \mathrm{~mm}$ for CSF, PADI should not be smaller than $14 \mathrm{~mm}$. Literature findings indicate that the reduction of this dimension below $14 \mathrm{~mm}$ negatively impacts the outcomes of surgical treatment [12].

AADI and PADI values are used to evaluate anterior and posterior subluxation and can be measured on lateral radiographs.
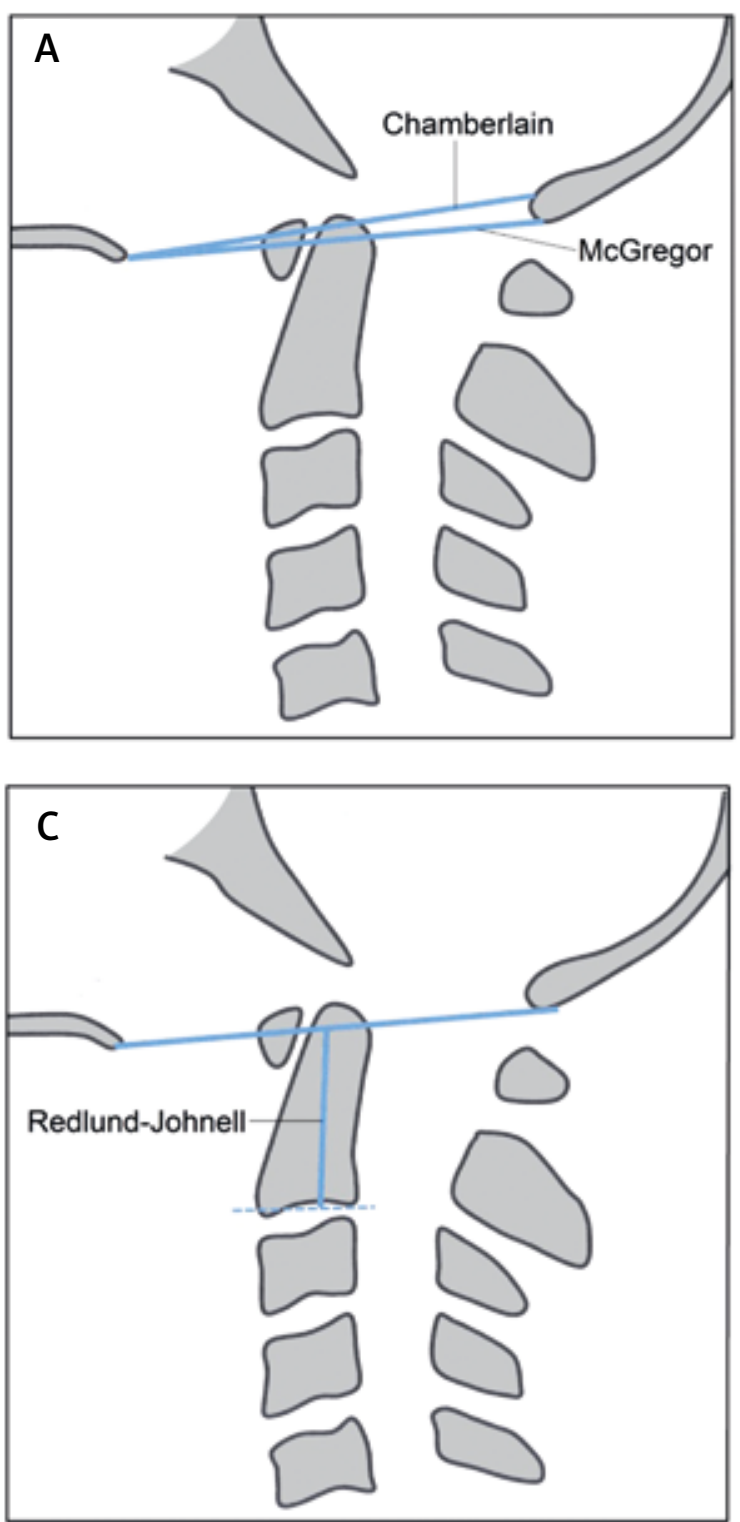

Radiographs through the open mouth aimed at the odontoid process are used to evaluate lateral subluxation. The displacement of C1 towards C2 by more than $2 \mathrm{~mm}$ can indicate clinically significant instability.

\section{Subaxial subluxation}

Subluxation in the lower joints of cervical spine usually accompanies the instability in C1-C2. Usually SAS is diagnosed when the radiograph in lateral projection shows horizontal displacement of vertebrae by more than $3.5 \mathrm{~mm}[14,15]$. However some authors consider that SAS should be suspected in the case of vertebrae
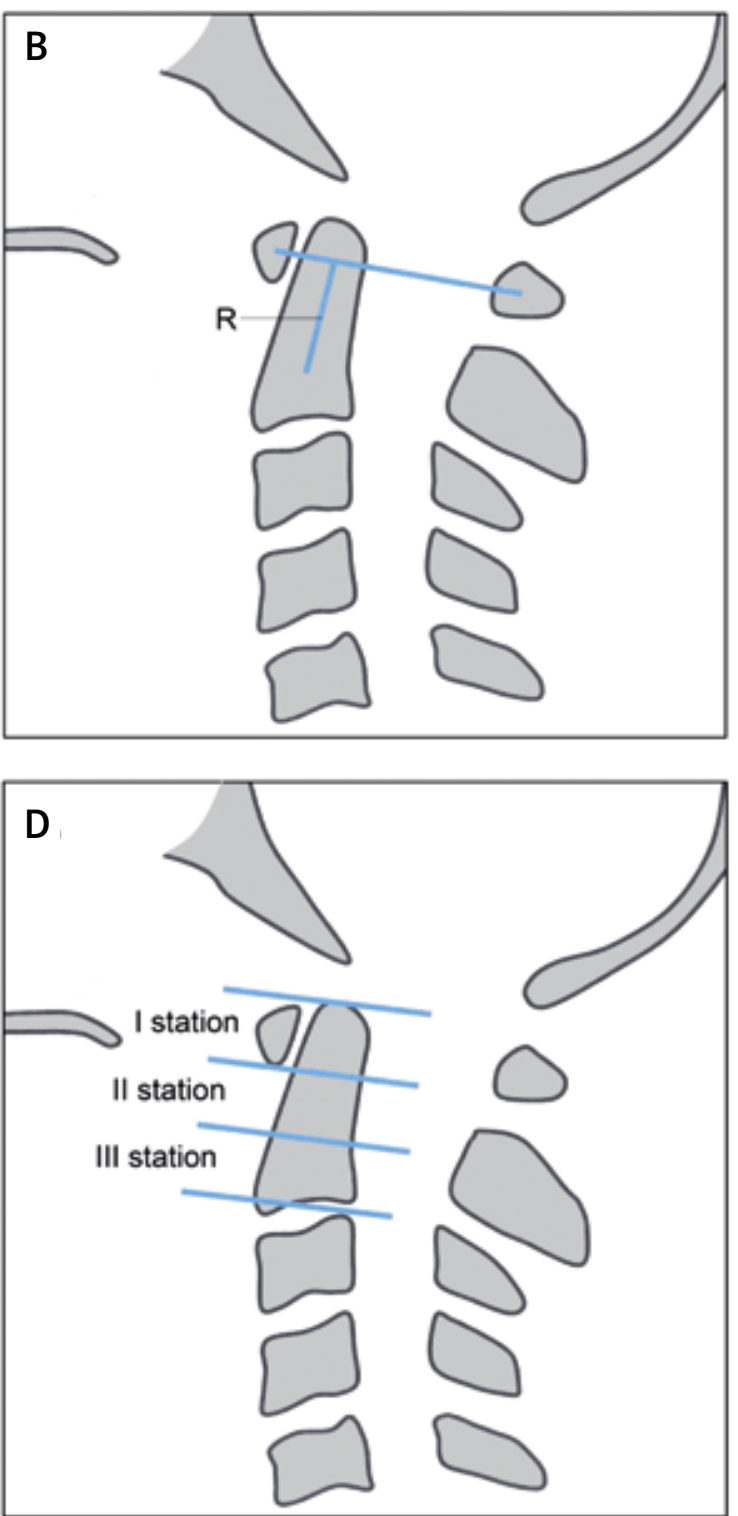

Fig. 2. Diagnostic criteria of cranial settling: chamberlain and McGregor lines (A); Ranawat criterion (B); Redlund-Johnell criterion (C); Clark station criterion (D). 
displacement by $2 \mathrm{~mm}$ and the displacement exceeding $4 \mathrm{~mm}$ is a sign of severe SAS $[1,16]$.

Similarly to the radiological assessment of atlanto-axial joint pathologies, the width of a spinal canal is an important parameter in the diagnosis of cervical spine lesions in C3-C7 region. It is considered that the value of space available for the cord (SAC) measured on lateral radiograph should not be smaller than $14 \mathrm{~mm}$ [12]. The distance is measured on lateral radiograph taken in neutral position, flexion and extension

\section{Cranial settling}

The assessment of the dens location with regard to foramen magnum on radiographs requires additional measurements. A number of methods have been developed to assess the degree of dens displacement. The oldest diagnostic criteria are based on Chamberlain and McGregor line (Fig. 2A) [17]. Chamberlain line is a line joining the posterior edge of hard palate with the back of the foramen magnum. The displacement of the tip of the dens by at least $3 \mathrm{~mm}$ above the line indicates basilar invagination. McGregor line connects the hard palate with the most caudal point of the occipital curve. If the tip of the dens lies more than $4.5 \mathrm{~mm}$ above this line it is indicative of basilar invagination.

Other popular diagnostic criteria include Ranawat criterion, Redlund-Johnell criterion and Clark station.

Ranawat criterion is based on two lines (Fig. 2B). One line connects the centre of the anterior arch with the centre of the posterior arch of C1 vertebra. The second line is drawn along the axis of the odontoid process, from the centre of the base of C2 vertebra to the intersection with the first line. The distance, marked on the diagram $1 b$ with the letter $R$, is the value used to assess the size of the invagination. The smaller is the distance,

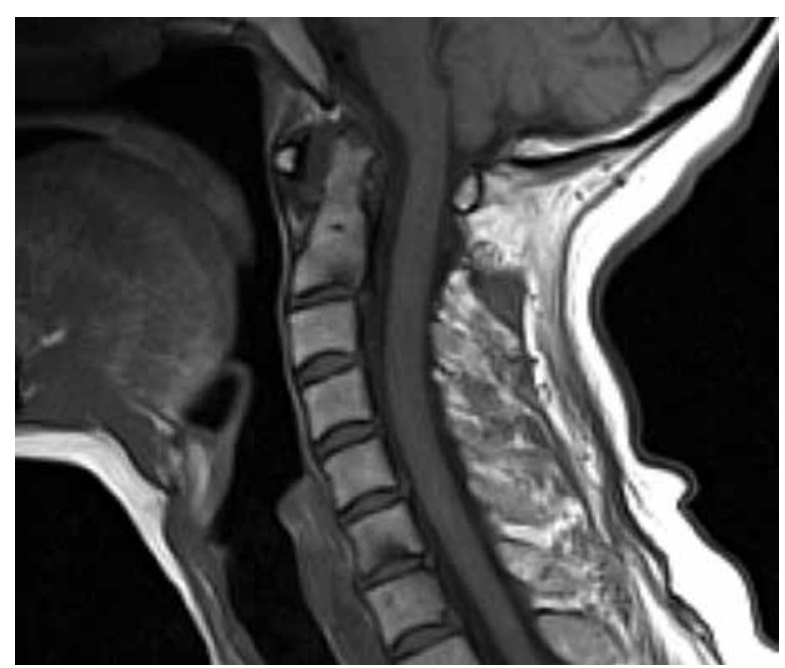

Fig. 3. Sagittal T1-weighted MR image. the larger is the invagination. Values of Ranawat criterion that are larger than $13 \mathrm{~mm}$ in women and $15 \mathrm{~mm}$ in men are assumed to be correct [18].

Redlund-Johnell criterion is the distance between the centre of the lower end plate of C2 to the McGregor's line (Fig. 2C). The distance of $34 \mathrm{~mm}$ in men and $29 \mathrm{~mm}$ or more in women is considered normal [19].

In the criterion developed by Clark, called Clark station, the dens, as viewed on the lateral radiograph, is divided into three equal parts (Fig. 2D). If the anterior arch of the atlas is in the second or third station the process of cranial settling is ongoing.

Despite a large number of criteria for basilar invagination, none has a satisfying characteristic of diagnostic value. Riew et al. [20] analysed the sensitivity, specificity as well as positive and negative predictive values of methods used for the cranial settling diagnosis. It was demonstrated that a single criterion is not sufficient to diagnose invagination. Therefore the combination of the Ranawat criterion, the Redlund-Johnell criterion and the Clark station was proposed. If any of the three criteria is positive, there is a strong probability of cranial settling (sensitivity of $94 \%$, negative predictive value of $91 \%$ ) [20].

\section{Computed tomography}

Computed tomography (CT) allows for a very precise assessment of bones structure of the whole cervical spine. The anatomy of the atlanto-axial joint is also much better visible that on plain radiograph where the image deteriorates due to the overlapping of bones structure. CT with multiplanar reconstruction is particularly recommended for patients with suspicion of basilar invagination. CT is also considered to be the best method for the visualization of bones erosion as well as atypical subluxation within the atlanto-axial joint, in particular lateral and rotary subluxation [21, 22].

Even though magnetic resonance is a better method of soft tissues imaging, CT can also be used to assess the inflammation of soft tissues in patients with contraindications for $M R$.

$\mathrm{CT}$ is also recommended in planning of surgical procedures as a method that allows for the selection of an appropriate technique and the size of implants.

\section{Magnetic resonance}

Magnetic resonance (MR) is a method of choice that is used for the assessment of cervical spine in patients with RA. This technique makes it possible - thanks to its three-dimensionality - to assess very precisely the location of all bone structures, in particular the location of the odontoid process with regard to foramen magnum. It is indispensable in the assessment of soft 

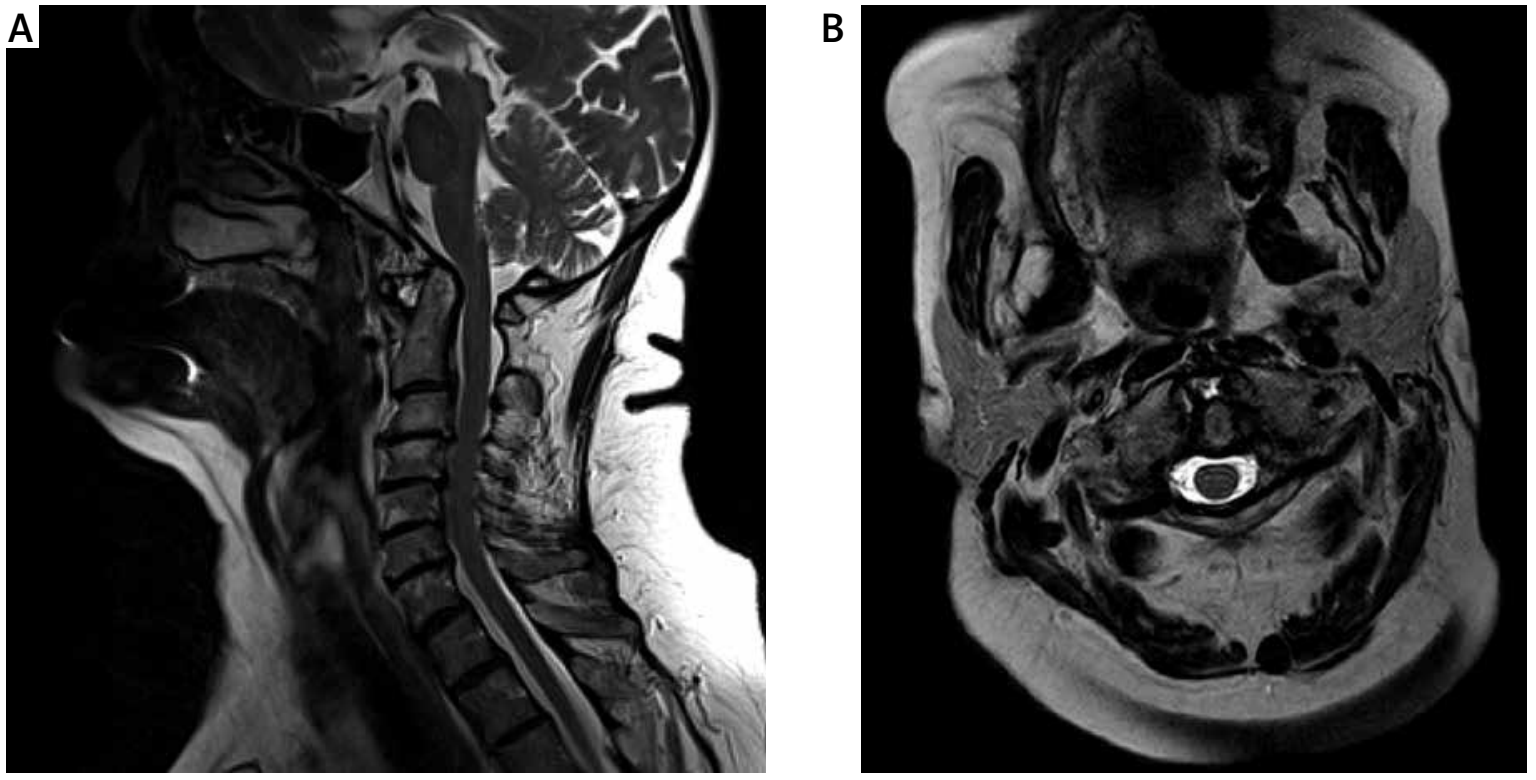

Fig. 4. Sagittal (left) and axial (right) T2-weighted MR images.

tissue. It allows for the detection, with high sensitivity, of inflammatory lesions in the joints: inflammation of the synovial membrane and the creation of pannus. It is also the best method for the detection of spinal cord compression.

As demonstrated by Dvorak et al. [23] in 2/3 of patients with AAS in the course of RA the pannus around the odontoid process is thicker than $3 \mathrm{~mm}$. Plain radiograph does not show the pannus, therefore the PADI measurement performed with this method can be misleading. Even though on a radiograph PADI is within normal limits the spinal cord compression can in fact occur, due to the presence of the pannus. That is why the role of magnetic resonance is invaluable since it makes it possible to measure the actual space available for the cord (SAC)

Test protocols for magnetic resonance of cervical spine include most often the following sequences T1-weighted spin echo (SE), T2-weighted fast spin echo (FSE), TIRM or STIR and DWI [24].

T1-weighted SE sequences are usually used to assess bone structures: the size, the shape and the location of vertebrae. It is also a basic, initial sequence to assess bone marrow oedema (Fig. 3).

T2-weighted FSE sequences are used to assess intervertebral disc space, nerve roots, spinal cord and articular surface. Pannus is also clearly visible on T2-weighted images - well-vascularized pannus gives particularly strong signal on a T2-weighted image (Fig. 4). T2-weighted sequences with fat saturation are in turn very helpful in more precise assessment of bone marrow oedema.
In cases of doubt, when there is a need to confirm an ongoing inflammatory process, T1-weighted images with fat saturation are obtained with the use of gadolinium contrast agent. These sequences make it possible to see different forms of pannus: hypervascularized, hypovascularized and fibrous pannus as well as to differentiate intraarticular exudate from the pannus [25, 26].

Besides the analysis of anatomical relations and the degree of tissue vascularization MR allows for the assessment of phenomena at cellular level. The example of one of the new techniques of magnetic resonance is diffusion-weighted imaging (DWI) which measures the motion of water molecules within intra- and extracellular fluid [27, 28]. The damage to spinal cord tissue architecture due to myelopathy (caused by spinal stenosis) leads to the disturbance in water molecules diffusion within the cord. These lesions can be observed on DWI images and on the apparent diffusion coefficient (ADC) maps. The DWI technique can also be used to assess the inflammation, replacing the imaging with contrast agent [29].

\section{Conclusions}

Although it seems that with the introduction of magnetic resonance as a diagnostic method, other imaging methods may be considered obsolete, both $\mathrm{CT}$ and plain radiography, which is the oldest and the simplest method, have not been entirely replaced. The advantages and disadvantages of individual methods are presented in Table II. Each of the methods has a specific use in the diagnosis of cervical spine lesions. 
Table II. Advantages and disadvantages of radiographs, CT and MR in imaging cervical spine lesions (based on [9])

\begin{tabular}{|c|c|c|}
\hline & Advantages & Disadvantages \\
\hline $\begin{array}{l}\text { Plain } \\
\text { radiographs }\end{array}$ & $\begin{array}{l}\text { - easily accessible } \\
\text { - low cost } \\
\text { - low radiation dose } \\
\text { - possibility of imaging in flexion and extension } \\
\text { - sufficient to assess the location of vertebrae }\end{array}$ & $\begin{array}{l}\text { - the assessment of anatomical details is difficult, in par- } \\
\text { ticular in atlanto-axial joint } \\
\text { - no possibility to assess non-calcified structures (soft } \\
\text { issues, spinal cord, pannus) }\end{array}$ \\
\hline CT & $\begin{array}{l}\text { - best method of bones assessment } \\
\text { - useful in planning surgical treatment }\end{array}$ & $\begin{array}{l}\text { - high cost in comparison with radiographs } \\
\text { - high radiation dose } \\
\text { - difficult assessment of soft tissues and spinal cord }\end{array}$ \\
\hline MR & $\begin{array}{l}\text { - best method of soft tissues and spinal cord } \\
\text { assessment } \\
\text { - high sensitivity and specificity in instability } \\
\text { assessment } \\
\text { - method of choice for patients with neurologi- } \\
\text { cal deficits }\end{array}$ & $\begin{array}{l}\text { - the most costly among all imaging methods } \\
\text { - possible contraindications: ferromagnetic implants, } \\
\text { artificial cardiac pacemakers, infusion pumps and medical } \\
\text { ventilators } \\
\text { - long exam duration } \\
\text { - in some cases sedation can be necessary (claustrophobia, } \\
\text { children) }\end{array}$ \\
\hline
\end{tabular}

Most authors admit that plain radiograph remains an initial imaging method, particularly in patients with no significant clinical symptoms. In the case of any lesions observed on plain radiograph, magnetic resonance is recommended. MR allows for diagnosis verification as it makes inflammatory lesions and possible spinal cord compression visible. European League Against Rheumatism (EULAR) clearly indicates that "Monitoring of functional instability of the cervical spine by lateral radiograph obtained in flexion and neutral should be performed in patients with clinical suspicion of cervical involvement. When the radiograph is positive or specific neurological symptoms and signs are present, MRI should be performed" [9].

Computed tomography is on the other hand particularly useful in surgical treatment planning.

The authors declare no conflict of interest.

\section{References}

1. Yurube T, Sumi M, Nishida K, et al. Incidence and aggravation of cervical spine instabilities in rheumatoid arthritis: a prospective minimum 5-year follow-up study of patients initially without cervical involvement. Spine (Phila Pa 1976) 2012; 37: 21362144.

2. Wasserman BR, Moskovich R, Razi AE. Rheumatoid arthritis of the cervical spine - clinical considerations. Bull NYU Hosp Jt Dis 2011; 69: 136-148.

3. Nguyen HV, Ludwig SC, Silber J, et al. Rheumatoid arthritis of the cervical spine. Spine J 2004; 4: 329-334.

4. Krauss WE, Bledsoe JM, Clarke MJ, et al. Rheumatoid arthritis of the craniovertebral junction. Neurosurgery 2010; 66 (3 Suppl): 83-95.

5. Neva $\mathrm{MH}, \mathrm{Häkkinen} \mathrm{A,} \mathrm{Mäkinen} \mathrm{H}$, et al. High prevalence of asymptomatic cervical spine subluxation in patients with rheu- matoid arthritis waiting for orthopaedic surgery. Ann Rheum Dis 2006; 65: 884-888.

6. Oda T, Fujiwara K, Yonenobu K, et al. Natural course of cervical spine lesions in rheumatoid arthritis. Spine (Phila Pa 1976) 1995; 20: 1128-1135.

7. da Côrte FC, Nevesn N. Cervical spine instability in rheumatoid arthritis. Eur J Orthop Surg Traumatol 2014; 24 Suppl 1: S83-S91.

8. Passos Cardoso AL, Da Silva NA, Daher S, et al. Evaluation of the Cervical Spine among Patients with Rheumatoid Arthritis. Rev Bras Ortop 2010; 45: 160-165.

9. Colebatch AN, Edwards CJ, Østergaard M, et al. EULAR recommendations for the use of imaging of the joints in the clinical management of rheumatoid arthritis. Ann Rheum Dis 2013; 72: 804-814.

10. Joaquim AF, Ghizoni E, Tedeschi H, et al. Radiological evaluation of cervical spine involvement in rheumatoid arthritis. Neurosurg Focus 2015; 38: E4.

11. Hohl JB, Grabowski G, Donaldson WF. Cervical deformity in rheumatoid arthritis. Semin Spine Surg, 2011; 23: 181-187.

12. Boden SD, Dodge LD, Bohlman HH, et al. Rheumatoid arthritis of the cervical spine. A long-term analysis with predictors of paralysis and recovery. J Bone Joint Surg Am 1993; 75: 1282-1297.

13. Lustrin, E.S, Karakas SP, Ortiz AO, et al. Pediatric cervical spine: normal anatomy, variants, and trauma. Radiographics 2003; 23: 539-560.

14. White AA 3rd, Johnson RM, Panjabi MM, et al. Biomechanical analysis of clinical stability in the cervical spine. Clin Orthop Relat Res 1975; (109): 85-96.

15. Wollowick AL, Casden AM, Kuflik PL et al. Rheumatoid arthritis in the cervical spine: what you need to know. Am J Orthop (Belle Mead NJ) 2007; 36: 400-406.

16. Yonezawa T, Tsuji H, Matsui H, et al. Subaxial lesions in rheumatoid arthritis. Radiographic factors suggestive of lower cervical myelopathy. Spine (Phila Pa 1976) 1995; 20: 208-215.

17. Chamberlain WE. Basilar Impression (Platybasia): A Bizarre Developmental Anomaly of the Occipital Bone and Upper Cervical 
Spine with Striking and Misleading Neurologic Manifestations. Yale J Biol Med 1939; 11: 487-496.

18. Ranawat CS, O'Leary P, Pellicci P, et al. Cervical spine fusion in rheumatoid arthritis. J Bone Joint Surg Am 1979; 61: 10031010.

19. Redlund-Johnell I, Pettersson H. Radiographic measurements of the cranio-vertebral region. Designed for evaluation of $a b-$ normalities in rheumatoid arthritis. Acta Radiol Diagn (Stockh) 1984; 25: 23-28.

20. Riew KD, Hilibrand AS, Palumbo MA, et al. Diagnosing basilar invagination in the rheumatoid patient. The reliability of radiographic criteria. J Bone Joint Surg Am 2001; 83-A: 194-200.

21. Czerny C, Grampp S, Henk CB, et al. Rheumatoid arthritis of the craniocervical region: assessment and characterization of inflammatory soft tissue proliferations with unenhanced and contrast-enhanced CT. Eur Radiol 2000; 10: 1416-1422.

22. Younes M, Belghali S, Kriâa S, et al. Compared imaging of the rheumatoid cervical spine: prevalence study and associated factors. Joint Bone Spine 2009; 76: 361-368.

23. Dvorak J, Grob D, Baumgartner H, et al. Functional evaluation of the spinal cord by magnetic resonance imaging in patients with rheumatoid arthritis and instability of upper cervical spine. Spine (Phila Pa 1976) 1989; 14: 1057-1064.

24. Sudol-Szopinska I, Urbanik A, Wojciechowski W, et al. Polish Medical Society of Radiology and Polish Society of Rheumatology Recommendations for Magnetic Resonance Imaging of Musculoskeletal Disorders in Rheumatology. Pol J Radiol 2015; 80: 259-265.

25. Stiskal MA, Neuhold A, Szolar DH, et al. Rheumatoid arthritis of the craniocervical region by MR imaging: detection and characterization. AJR Am J Roentgenol 1995; 165: 585-592.

26. Sommer OJ, Kladosek A, Weiler V, et al. Rheumatoid arthritis: a practical guide to state-of-the-art imaging, image interpretation, and clinical implications. Radiographics 2005; 25: 381 398.

27. Ellingson BM, Salamon N, Holly LT. Advances in MR imaging for cervical spondylotic myelopathy. Eur Spine J 2015; 24 Suppl 2 197-208.

28. Song T, Chen WJ, Yang B, et al. Diffusion tensor imaging in the cervical spinal cord. Eur Spine J 2011; 20: 422-428.

29. Jeromel M, Jevič V, Serša I, et al. Quantification of synovitis in the cranio-cervical region: dynamic contrast enhanced and diffusion weighted magnetic resonance imaging in early rheumatoid arthritis - a feasibility follow up study. Eur J Radiol 2012 81: 3412-3419. 